\title{
Experiences of postdocs and principal investigators in physics education research postdoc hiring
}

\author{
Alexis V. Knaub, ${ }^{1}$ Manher Jariwala, ${ }^{2}$ Charles R. Henderson, ${ }^{3}$ and Raina Khatri ${ }^{4}$ \\ ${ }^{1}$ Department of Physics and Astronomy, Michigan State University, East Lansing, Michigan 48824, USA \\ ${ }^{2}$ Department of Physics, Boston University, \\ 590 Commonwealth Avenue, Boston, Massachusetts 02215, USA \\ ${ }^{3}$ Department of Physics, Western Michigan University, \\ 1903 W. Michigan Ave., Kalamazoo, Michigan 49008, USA \\ ${ }^{4}$ STEM Transformation Institute, Florida International University, \\ 11200 SW 8th Street, Miami, Florida 33199, USA
}

(Received 7 March 2018; published 20 June 2018; corrected 9 August 2018)

\begin{abstract}
Postdoc positions, intended to be advanced or continued research training in a field, are a part of the physics education research (PER) enterprise yet little is known about them. PER postdocs differ from their traditional physics counterparts in that they may have different education and research experiences. This study examined the types of postdoc positions available as well as what hiring is like. To determine the types of postdoc positions available, we used the advertisements posted in PERJobs blog. To learn more about hiring practices, interviews were conducted with both principal investigators (PIs) and current and former postdocs. Results show that many PER postdoc positions have been available since 2008, with many of these advertisements indicating that the PI will consider hiring someone with a physics or a PER or science, technology, engineering, or mathematics education background. The interviews indicate that there is no typical way for hiring PER postdocs. Some aspects that PIs consider include the background of the candidates and how well the candidates fit in with the group. Postdocs likewise consider whether they like the research group when accepting offers. For both, having ties to the PER community is important for hiring. Overall, PIs and postdocs have been satisfied. Postdocs who were originally in traditional physics have felt that being a PER postdoc has allowed them to transition to PER. In giving advice, both PIs and postdocs reiterate the importance of connecting to the community, evaluating the postdoc position as a stepping stone in the career trajectory, and holistically considering candidates.
\end{abstract}

DOI: 10.1103/PhysRevPhysEducRes.14.010152

\section{INTRODUCTION}

A postdoctoral research position can be an important part of the STEM career trajectory. These positions provide additional mentored time for nascent researchers to further hone research skills and establish themselves in the field. Postdocs also provide valuable intellectual labor to support principal investigators' (PIs) projects. In discipline-based education research (DBER) fields such as physics education research (PER), these postdoc positions are becoming more common. Unlike traditional science, technology, engineering, or mathematics (STEM) disciplines, postdocs in DBER have a variety of backgrounds. Some have a $\mathrm{Ph} . \mathrm{D}$. in a DBER field and see the postdoctoral position as a continuation of this work. Some, however, use these

Published by the American Physical Society under the terms of the Creative Commons Attribution 4.0 International license. Further distribution of this work must maintain attribution to the author(s) and the published article's title, journal citation, and DOI. positions to support their transition from traditional STEM research into DBER (e.g., condensed-matter-trained Ph.D. recipient turned PER scholar). Examples of how DBER postdoc positions have supported career transitions from STEM to DBER include the short-lived NSF program Postdoctoral Fellowships in Science, Mathematics, Engineering, and Technology Education (PFSMETE) [1] and the Carl Wieman Initiative [2]. There are also DBER postdocs whose doctoral degrees are in the social sciences who are interested in entering DBER.

Given the significant differences between traditional STEM postdoc positions and DBER postdoctoral positions, we were interested in learning more about DBER postdocs. We focused on hiring, because it serves as the gateway to becoming a postdoc. We focused on PER because it is one of the oldest DBER fields and has a relatively long history of postdoc hiring. In this qualitative study, we examined hiring practices to gain an understanding of how PIs make their hiring decisions, how postdocs choose their positions, and whether current hiring practices support satisfactory experiences for both PIs and postdocs. 


\section{LITERATURE REVIEW}

\section{A. Postdoctoral researchers}

The purpose of postdoc positions is to provide additional training and opportunity for doctoral recipients and fulltime, skilled research labor for PIs [3,4]. Although these positions are common within traditional STEM and have been for decades, there are concerns regarding the postdoctoral system. These concerns include whether these positions are truly training positions intended to provide additional support and mentoring before the postdoc transitions to work that is more independent [4]. The National Academies' Committee to Review the State of Postdoctoral Experience in Scientists and Engineers [3] reported that they have called for reforms in the postdoctoral system since 1969. The National Academies' Committee [3] questioned whether it is "necessary for someone to remain in training until their mid-30s before being qualified for his or her chosen career track" (p. 1), whether there is "an appropriate balance between the number of postdoctoral researchers that are trained and the number of jobs that require postdoctoral training" (p. 1), and whether the low status of postdoctoral researchers is a "possible disincentive to undergraduates and graduate students who are considering independent research careers" (p. 1). Thus, it is not clear that postdoc positions are functioning as originally intended.

Postdocs are not as common in PER as in traditional physics, although they have existed at least since the mid to late 1990s (e.g., the PFSMETE program). There may be a growing population of PER and other DBER postdocs. The National Research Council Discipline-Based Education Research (DBER) report suggests that individual DBER fields (e.g., PER), offer postdoctoral opportunities to advance the field of DBER [5]. PER postdocs may become more common as the field grows and more individuals are seeking jobs [6].

PER postdocs are unique from their traditional physics counterparts. In traditional physics, postdocs have Ph.D.'s in that physics subdiscipline or one very closely related to their postdoctoral work. PER postdocs have doctoral degrees in traditional physics, PER, or a social science (e.g., psychology). They enter the field at different points, often during graduate school, but some also do enter PER in their postdoctoral position [7]. Further complicating the situation, PER doctoral students can earn degrees from either physics departments or schools or colleges of education [8]. All of this suggests that PER postdocs have diverse educational experiences and backgrounds. Thus, this introduces additional challenges to the postdoctoral enterprise.

\section{B. Hiring practices}

There are few articles written about postdocs, hence the National Academies has indicated this as an area where more study is needed. The few articles that exist address the experiences of particular populations (e.g., international postdocs [9], female postdocs [10]) or issues with the postdoctoral enterprise (e.g., whether it results in a career $[11,12])$. These articles do not examine hiring practices for postdocs.

The only literature that we could find that addresses postdoc hiring is a guide from biology education research (BER). The authors are PIs themselves and interviewed an unspecified number of PIs to inform their guide [13]. According to the authors, hiring BER postdocs is similar to hiring traditional biology postdocs in that the candidate should have research and communication skills along with general skills, such as being organized and being able to work both in a group and independently [13]. The authors value seeing at least one publication, regardless of the publication's content: "We placed equal value on publications in biology research and BER" [13]. They advise that candidates have strong letters of recommendation and that a "strong commitment to education is a distinct and highly important consideration in the hiring of BER postdoc" [13]. Demonstrating a commitment includes engaging in BER via research projects or being well read in the literature, although the authors also believe that having research experience in BER will become more important as the number of BER Ph.D. recipients increases [13]. In terms of finding a position, suggestions include using one's professional network, introducing oneself to researchers in the BER community, and subscribing to relevant list-servs.

Because of the lack of postdoc-specific hiring literature, we focused on general hiring literature because it is well established. Academic hiring literature tends to focus on tenure-track hiring, which is somewhat different from postdoc hiring as tenure-track positions are intended to be permanent.

Hiring an employee is a process with many decisions, from conceptualizing what the job is to selecting candidates for interviews to making an offer. Defining important qualifications, skills, and experiences for the successful hire is a key step not only for those involved with hiring but also for the prospective candidates looking at job advertisements [14]. Having standards that are too high or too low can create issues. Standards that are too high can result in deterring suitable candidates or hiring overqualified employees who may become dissatisfied if their skills are not used, while standards that are too low may mean employees cannot do the job $[14,15]$.

When hiring, employers use some criteria to determine whether a candidate might be suitable. Those in charge of hiring can evaluate candidates to see whether they are a fit for the job (e.g., have skills that are needed for the position) or a fit for the organization [16]. "Fitting in" is not necessarily being demographically similar (e.g., being of the same race or gender) but can also include having similar interests to the current employees [17]. The rationale for hiring for organizational fit is that employees who are a 
good fit tend to be happier with their jobs [16,18], more productive [16], and are less likely to leave the position [14]. However, an employee who is not a good organizational fit does not always leave. Employees who are not good organizational fits may remain if they perceive there are no alternative opportunities [18].

Although there are benefits to hiring based on organizational fit, it can introduce issues. Hiring managers may end up hiring someone similar to themselves [17]. For an organization, this could result in employees with homogeneous perspectives and leave the organization with weaknesses and inflexibility to adapt to changes [18]. Heterogeneity among group members is also beneficial to innovation [19]. This may be particularly important to research groups seeking to develop novel projects or to gain a different perspective on their work.

To evaluate candidates, hiring managers can use a few means. One way is using interfirm ties (i.e., two organizations have individuals that interact with one another) to influence hiring decisions [20]. Interviewing is a common method for evaluating candidates, though there is significant variance in this practice. The number of interviews may differ depending on organizations or positions. For hiring that considers fit in the organization, hiring may involve multiple parties involved, such as team members, and multiple parts to ensure that the successful candidate can fulfill the basic technical skills of the job as well as "soft" skills such as teamwork capabilities [16]. Although labor intensive, a multistage interview allows for candidates and prospective employers to know each other better [16]. Interviews can be structured, with the same set of questions asked in the same order for all candidates, or unstructured, with a more conversational appearance and that do not follow the same format [21].

Although much of the literature covers hiring from the organization's perspective, hiring is a two-way process. Candidates are also making decisions on their interest in the position and whether to accept an offer. When making final decisions, candidates may be more interested in the fit for the job rather than the fit for the organization [22]. Interviewers can impact candidates' interest. Warm and friendly interviewers have a positive impact on candidates' perception of the job and can help alleviate candidate anxiety [23].

\section{Challenges in hiring}

One concern regarding hiring is biased practices. Recruitment strategies may only work for particular populations, thus excluding potential candidates [24]. The interview process itself can have biases as well. Structured interviews can eliminate some of the bias hiring managers might have towards candidates from marginalized backgrounds [21]. Some people may be well suited for the job but interview poorly. Skills-based assessments may be useful to evaluate candidates if otherwise suitable candidates lack interview experience [24]. However, skillsbased assessment introduces other issues. They can dissuade high status candidates from applying, particularly at lower-status organizations [25].

\section{Summary and research gap}

In traditional STEM fields, postdoc positions provide further research training. For PER postdocs, these positions may provide further research training or allow for career shifts from traditional physics to PER. For PIs, these positions support their research projects by employing highly skilled researchers. Little is known about traditional STEM postdocs, although there is a general sentiment that the postdoctoral enterprise should be improved. Even less is known on PER or DBER postdocs, although they appear to be a growing workforce. While the BER guide's advice is likely applicable to PER, its purpose is to deliver advice to graduate students who are considering becoming BER postdocs. The guide does not delve into the specifics of hiring or explore postdocs' experiences with hiring.

Literature indicates that hiring is a complex process where those hiring should consider how the position is presented in advertisements and the criteria that informs decisions. Hiring managers should consider the technical skills needed for the position as well as interpersonal relations with prospective hires and current employees, commonly referred to as "fit." While the literature does indicate fit is important, hiring managers should also be aware that fit can leave organizations with a homogenous perspective that does not allow for innovation. Hiring for fit can also introduce biases that may lead to excluding otherwise suitable candidates. Specific to the context of PER postdoc hiring, there may be suitable candidates who are not considered due to their educational background.

Although the BER guide suggests that hiring DBER postdocs is quite similar to their traditional counterparts, there are some key differences. Hiring DBER postdocs may make the general hiring process even more complex as there are additional variables introduced. Using PER as an example, there may be diverse candidates hailing from doctoral programs in PER, science education, social sciences, or traditional STEM. With such diversity in background, it is unclear how PIs, who act as hiring managers, make hiring decisions. Unlike their traditional STEM counterparts, PER postdocs may be new to the field or the tasks required in the position (e.g., education research, program management) and may have few experiences suggesting they will flourish. Similarly, PER postdocs who are new to the field may not know how to determine whether a position will support their career goals.

While hiring qualified postdocs who are capable of doing the job is always important regardless of the field, it may be especially important for PER. Although academic field creation is nebulous, PER shows signs of becoming an established field. Signs of an established academic field 
include a doctoral-level degree [26,27], a professional organization [26,28,29], and a research journal [28,29]. PER has all of these elements. Having these elements is not sufficient to be a field, as emerging fields must produce quality work [29]. As PER postdocs are responsible for many important research activities, ensuring that those hired are able to produce quality work can help support this emerging field.

\section{E. Research questions}

We are interested in understanding how PIs are hiring PER postdocs, the hiring experiences of candidates, and whether the hiring process is adequate for both PIs and postdocs to have fruitful experiences.

Our key research questions are as follows:

(1) What types of PER postdoc positions have been available?

(2) Regarding PIs:

(a) How do PIs find candidates?

(b) How do PIs determine whether candidates are likely to be successful?

(c) How satisfied are PIs with the postdocs they hired?

(3) Regarding postdocs:

(a) How do postdoc candidates find potential positions?

(b) How do postdoc candidates decide whether to accept an offer?

(c) How satisfied are hired postdocs with their postdoc experiences?

\section{METHODS}

For this study, we define a PER postdoc as someone who holds a doctoral degree and is working in a training position in PER. Indicators of being in PER include the following:

- Conducting research related to the teaching and/or learning of physics

- Participating in PER professional organizations and conferences [e.g., American Association of Physics Teachers (AAPT), American Physical Society (APS) sessions with education research]

- Publishing articles in journals aimed at the PER community (e.g., Physical Review Physics Education Research, American Journal of Physics)

- Collaborating with PER researchers

- Being supervised by a PER researcher

While we expected that PER postdocs will have many of these indicators, we do not expect that they will have all.

\section{A. Job advertisement study data collection and analysis}

To understand what types of PER postdoc positions exist and the types of candidates PIs were interested in, we used the PERJobs [30] database. This site was created specifically for PER jobseekers and likely hosted the majority of advertised postdoc positions in PER. Advertisements date back as far as 2007. We did not include 2007, because PERJobs started during 2007 and therefore may not have all PER postdoc positions offered during 2007.

Our sample consisted of advertisements that were for research postdoc positions in PER. We included only positions that defined a primary research component to ensure that the position was not just a program manager or instructor position. Occasionally, advertisements were relisted and noted as such; those advertisements were excluded.

Advertisements were coded by Knaub and Khatri using a priori codes. Codes included which educational backgrounds would be considered (e.g., whether one needed a PER or STEM education doctoral degree), the funding agency, and the population studied in the research.

\section{B. Hiring study \\ 1. Sample}

Our sample consists of researchers who were working as postdocs and PIs who were hiring postdocs. We generated a list of PIs based on the PERJobs job advertisement study and our own knowledge of PIs who were hiring. Using these methods, we identified 66 PIs total. For PIs, we were interested in PIs who had conducted at least two rounds of hiring in the past five years so that they had multiple experiences to draw upon and to reflect contemporary hiring. Again, using the list of PIs and our own knowledge, we found 28 PIs at 18 different institutions in the U.S. who met these criteria.

Finding postdocs involved more work as that list was not readily available. We initially created a list of postdocs, looking at research group websites where we knew postdocs had been hired as well as adding postdocs we knew. However, we believed the list may not have been complete. We knew abstractly that some institutions had smaller groups that may have only one postdoc. Large groups may not keep a publicly available record of former members. Thus, we sought information from the PER community. During June 2016, we asked the following list-servs to contribute to the postdoc list: PHYSLRNR, PERTG, and YOUNG-PER. At the top of the list we provided the definition of a PER postdoc based on the literature on postdocs and field creation; this definition is at the beginning of Sec. III.

We requested that members of the list-servs provide the names and postdoc institution of postdocs from 2013 through the present time of the study (June 2016). The rationale for the time period was to reflect contemporary hiring practices (e.g., internet use) and so that interviewees would have fairly recent memories regarding hiring. At the time of data collection, the list included 52 people and 55 individual postdoc positions across 20 U.S. institutions and nine individual positions from three international institutions from January 2013 through June 2016. We distinguish 
individuals from positions because three individuals were postdocs at two different institutions.

We chose to only consider PIs and postdocs from U.S. postsecondary academic institutions. Hiring at nonUS and non-academic institutions is often different than U.S. academic institutions. International institutions may be governed by different hiring policies and laws than U.S. institutions. Postdoctoral fellowships awarded by national organizations have clear application materials and criteria.

We purposefully selected PIs from a variety of U.S. institutions so that the data did not reflect one group's perspective or experiences. Similarly, we selected individuals who worked as postdocs at a variety of institutions.

We interviewed 20 individuals from 13 institutions. The sample breaks down as follows:

- Postdocs: 12 interviewed, 20 invited for an interview

- PIs: 7 interviewed, 16 invited for an interview

- 1 person who was interviewed as both a postdoc and a PI. This PI had been a postdoc in the time window under consideration. They were asked about both their PI and postdoc experiences.

While the sample is not evenly split among categories, there is variety among interviewees. The postdocs were primarily from PER or DBER Ph.D. programs (9 out of 13) but a few were from traditional physics Ph.D. programs (4 out of 13). Most (7 out of 8) of the PIs were from physics departments, which may be reflective of where PER faculty are hired. Five interviewees (three postdocs, two PIs) were from one institution. All other institutions had one or two interviewees.

\section{Interview structure and analysis}

Knaub conducted approximately $30 \mathrm{~min}$, semistructured interviews via phone or video chat. For PIs, the interviews delved into how PIs find postdoc candidates, how they make choices regarding who gets interviewed and hired, any changes they have made to the hiring process, and whether they have been satisfied with their postdocs. For current and former postdocs, we asked why they sought postdoc positions, how they found their positions, what the interview process was like, how they selected their postdoc positions, and whether they were satisfied with the job. (The complete sets of questions are listed in the Appendices.)

Interviews were audio recorded. We took detailed notes on the interviews. Both coders (Jariwala and Knaub) checked one another's notes to ensure all details were included.

We generated some a priori thematic codes based upon the literature and our knowledge of hiring. As we began coding the data, we also included emergent codes. The coders individually coded the data and then worked to find consensus for any discrepancies.

\section{Limitations}

A primary limitation of this study is that we only interviewed successful candidates who accepted an offer. Prospective candidates who did not receive any offers might collectively display different patterns. That information would be useful to better prepare prospective candidates or to reveal an issue with hiring. However, there is no good way to find this population.

Similarly, successful candidates who did not accept the offer might have insights on hiring and what led them to decline the offer. A few of our interviewees did receive multiple offers and declined; when possible, we included those data.

\section{RESULTS}

\section{A. What PER postdoc positions have been available?}

From 2008 through 2015, we found that 144 positions were advertised in PERJobs blog by 67 different PIs. In our PI count, we did not include listings where the contact person was an administrative staff person. Positions advertised typically indicated the PI. If not, we attempted to identify the PI online. Eleven of the postings were for nonU.S. institutions. The number of jobs by year is shown in Fig. 1.

Most advertisements did not specify which organization funds the postdoc position. Of those that did, the NSF ( $N=33$ of the 40 that specified) funded the majority.

When the job advertisement provided details regarding the research being conducted, we coded positions by the population of interest. The majority $(N=99$ or $68.8 \%)$ of positions indicated that the postdoc would be studying only undergraduate students. Fifteen positions studied only faculty in postsecondary education. Seven positions mentioned studying both faculty and undergraduates. Fifteen advertisements did not provide details on the population that the research studied.

The majority of advertisements $(N=114$ or $79.2 \%)$ described the doctoral educational background prospective

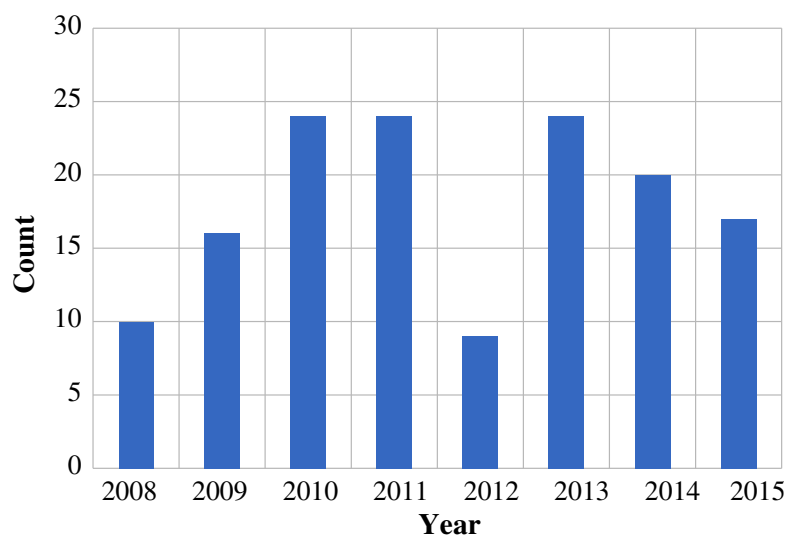

FIG. 1. Number of postdoc positions advertised in PERJobs blog, by year. 
TABLE I. The doctoral education backgrounds prospective postdocs should have.

\begin{tabular}{lcc}
\hline \hline Ph.D. & Count & $\begin{array}{c}\text { Percentage of } \\
\text { advertisements }\end{array}$ \\
\hline PER or STEM education or physics & 68 & 59.6 \\
PER or STEM education only & 21 & 18.4 \\
Physics only & 17 & 14.9 \\
Education only & 5 & 4.4 \\
PER, physics, or education & 1 & 0.9 \\
PER or education & 1 & 0.9 \\
Social sciences & 1 & 0.9 \\
\hline \hline
\end{tabular}

postdocs should have. These results are in Table I. According to the advertisements, most PIs (59.6\%) would consider a person from a PER or STEM education or physics background.

From the interviews of both PIs and postdocs, the primary responsibilities for most postdocs were to do educational research (i.e., creating new knowledge) as noted in 15 of 21 interviews. ${ }^{1} \mathrm{~A}$ few postdocs were involved in course transformation $(N=4)$ (e.g., integrating a new teaching practice) and education research and development (e.g., designing and improving upon an educational product) $(N=3)$ that culminated in or improved upon a product (e.g., designing curriculum, implementing a program).

\section{B. PI results}

In both Secs. IV. B and IV. C, "postdocs" refer to interviewees who were asked questions regarding their postdoc experiences. Some of them are now working in other jobs.

\section{How do PIs find candidates?}

Table II displays the results of where PIs search for postdocs. Although all PIs noted that they posted advertisements to DBER-specific websites (e.g., PERJobs blog), some of the PIs in this sample had mixed experiences with such sites. One PI found that these sites are quite useful, while another PI felt that "word of mouth is the best advertising out there." A third PI said these websites tend to attract people they already know in the PER community, which makes sense as these websites are known resources. The other five did not mention anything negative or positive regarding these websites.

Several PIs indicated that they had difficulties finding candidates. Some difficulties were linked to attracting candidates. One PI noted that the institution's location and the group are not as attractive to potential applicants as other groups and places. A second PI said that the market

\footnotetext{
${ }^{1}$ Although we interviewed 20 individuals, we are considering the number of interviews as 21 because one interviewee discussed both their experiences as a PI and a postdoc.
}

TABLE II. Where PIs search for postdocs. Interviewees used multiple methods, so the totals are much larger than the sample size.

\begin{tabular}{lc}
\hline \hline & PI $(N=8)$ \\
\hline Close tie (e.g., advisor, colleague) & 2 \\
Weak ties (e.g., acquaintances) & 2 \\
Networking at a professional conference & 3 \\
DBER-specific websites (e.g., PERJobs blog) & 8 \\
General academic job sites & 4 \\
List-servs & 3 \\
\hline \hline
\end{tabular}

for good postdocs is competitive because strong candidates sometimes take faculty positions. One postdoc interviewee had a similar observation: "I would guess that some of the strongest candidates finishing Ph.D.s go straight into faculty positions, so the pool of postdocs is not as strong as it could be. Some of the postdocs had weaker training or dissertations, through no fault of their own." Timing can be an issue too. Another PI noted that they cannot do much of a search because they find that they need a postdoc to almost start immediately when they receive grants. They estimated that a search can take almost 5 months to hire a postdoc if they consider nonlocal candidates.

\section{How do PIs determine whom to hire?}

As with most job searches, PIs generally required postdoc applicants to submit materials. Both PIs and postdocs provided information regarding application materials. These data are displayed in Table III. The six applicants who did not need to submit CVs were already employed by their postdoc institution. Although most applications require a $\mathrm{CV}$ and cover letter, other requirements were highly variable.

Once applications are received, they must be reviewed, often to determine whether a candidate is offered an interview. For some PIs, it is immediately clear when an applicant is not suitable. The applicant may not meet the listed requirement (e.g., not having a doctoral degree in PER or DBER). Another indication that the application is not suitable is when the applicant expresses interest in teaching rather than research. This issue was attributed to a

TABLE III. Application materials required for PER postdoc positions.

\begin{tabular}{lcc}
\hline \hline & Count & Percentage $(N=21)$ \\
\hline CV & 15 & 71.4 \\
Cover letter & 12 & 57.1 \\
References (e.g., recommendation & 8 & 38.1 \\
$\quad$ letters, list of names) & & \\
Research statement & 4 & 19.0 \\
Teaching statement & 4 & 19.0 \\
Writing sample & 1 & 4.8 \\
\hline \hline
\end{tabular}


misconception that PER involves teaching or improving one's teaching, rather conducting research or, as one PI stated, “...generating new knowledge." Another PI estimated that $50 \%$ of the applications they receive for postdoc positions are from applicants looking for a teaching position. Interestingly, two of the postdoc interviewees noted that they specifically included references that could speak to their teaching abilities. While one of the postdocs had a position where there was a teaching component, it is not clear the other postdoc's position required teaching.

After confirming basic requirements are met, a PI might still need to whittle down the number of candidates to be interviewed. One PI used a loose rubric to help organize information about the candidate. This PI explained that it helps identify what is important for the position and reduces bias. The example the PI gave is that they tended to lean towards candidates who have a similar educational background to the PI before developing the rubric.

References are sometimes part of the application materials. Reference letters and phone calls were requested at different points. PIs sometimes asked for letters or ask for a list of references they can contact; there was no described preference. Sometimes, they were reviewed before meeting the candidates, sometimes after. PIs used references to understand more about the candidate including research capabilities and whether there are any negative aspects. One PI emphasized that reference letters should convey relevant information: "Sometimes, you get letters that talk about how smart someone is. That does not really help me. Are they independent? That's really important in our group because we tend to be hands off with our postdocs." Several PIs noted that if they know the reference, they take note of that.

Table IV summarizes the data regarding job interviews. Except for the first line, all percentages were found by dividing by 17, the number of PIs and postdocs who noted a job interview. Most postdocs and PIs reported that interviews occurred, with many having multiple interviews. Approximately half of the interviews were virtual (e.g., Skype) and the other half were in-person. A quarter had both in-person and virtual interviews. Sometimes in-person interviews occurred before virtual interviews, sometimes vice versa. In-person interviews that occurred before virtual

TABLE IV. Summary of postdoc job interviewing.

\begin{tabular}{lrc}
\hline \hline & Count & $\begin{array}{c}\text { Percentage (out of 17, } \\
\text { unless noted) }\end{array}$ \\
\hline Had at least one interview & 17 & 81.0 (out of 21) \\
Multiple interviews & 9 & 52.9 \\
At least one virtual interview & 11 & 64.7 \\
$\quad$ (e.g., Skype) & & \\
At least one-person interview & 10 & 58.8 \\
$\begin{array}{l}\text { Had both an in-person and } \\
\quad \text { virtual interview }\end{array}$ & 4 & 23.5 \\
\hline \hline
\end{tabular}

interviews appear to be a bit informal and may be done over lunch or coffee. Those who conducted in-person interviews felt they were valuable to get to know the candidates. As one PI noted, "Having someone there for a day gives you a lot more information than speaking with them for an hour and trusting the letters of evaluation." The PIs who conduct in-person interviews were enthusiastic about their usefulness. However, three PIs noted that they lack funding to conduct in-person interviews.

Four of the interviewees $(23.5 \%$, out of the 17 who indicated an interview occurred) noted that an in-person interview related to postdoctoral hiring occurred at a conference (e.g., AAPT). The contexts varied from interviews for a specific position to more informal conversation between the PI and the prospective postdoc where a position was not currently available. These meetings were not always about a specific position, but a way for prospective postdocs to get to know different PIs and vice versa. One PI is a strong proponent of these more casual interviews: "a formal interview setting is so stilted that you often don't get a feel for these things."

Table $\mathrm{V}$ displays the interview activities PIs and postdocs reported. As to be expected, the PI was involved with the interviews. Many PIs also involved other members of the project team or the research group. Interview questions and activities varied, though many are research related (e.g., giving a research talk, answering questions regarding the position, questions regarding non-PER research). Most interview activities were seen as relevant and good practices, but skills-based activities were met with mixed views.

Skills-based activities varied. Some PIs considered these activities secret, so the interviewee could not share what the activity was. From what could be described, activities include writing and/or data analysis with the intention of demonstrating how a candidate approached research. While one PI was enthusiastic about skills-based interview activities, another said they have abandoned the practice because they received feedback from a hire that the activity was

TABLE V. Summary of interview activities.

\begin{tabular}{lcc}
\hline \hline & & $\begin{array}{c}\text { Percentage } \\
\text { Count }\end{array}$ \\
& 17 & 100 \\
\hline Candidate met with PI & 11 & 64.7 \\
$\begin{array}{l}\text { Candidate met members of the group or } \\
\quad \text { project }\end{array}$ & & \\
Candidate answered questions related to & 8 & 47.1 \\
$\quad$ PER and the position & & \\
$\begin{array}{l}\text { Candidate answered questions related to } \\
\quad \text { non-PER research }\end{array}$ & 5 & 29.4 \\
$\begin{array}{l}\text { Candidate gave a research talk } \\
\text { Candidate worked on a skills-based activity }\end{array}$ & 4 & 23.5 \\
$\begin{array}{l}\text { Candidate answered questions related to } \\
\quad \text { soft skills (e.g., how well does one work }\end{array}$ & 3 & 17.6 \\
$\quad$ in a group) & & \\
\hline \hline
\end{tabular}


frustrating. The hire was not sure what the PI wanted in the activity and finding time to complete it was challenging.

If an interview is conducted, the interview plays an important role in how PIs make their hiring decisions. Most PIs $(N=7$ out of 8$)$ reported that the primary purpose of the interview is to see the skills that the candidates have, with two reporting that they want to see what the candidate's personality is like. They were interested in how candidates approach research problems and whether the candidate is enthusiastic to work in PER. PIs also noted that interviews are an opportunity for candidates to inquire about living in the geographic area and learn more about the research group.

When evaluating candidates, PIs were interested in whether the candidate would fit in with the group $(N=8)$ and had technical skills to do the work $(N=7)$. PIs felt that involving others in the interview process is important, because group members such as graduate students can observe things that the PI may not have seen. For example, one PI recalled that graduate students observed a candidate had disdain for collaborating with graduate students. Additionally, PIs were interested in whether the postdoc position supports the candidate's career goals. They wanted the postdoc position to help launch the candidate's career.

As to how they make their decisions, there is much variation. One PI pointed out: "You can interview and talk to lots of people, but you never really know for sure." To make more informed choices, three PIs used some form of a rubric and four discuss the interviewee with others. One PI surveyed group members to elicit opinions on the candidate.

Sometimes, it is clear which candidate should receive an offer. The candidate has skills that align better with the project, the candidate is prepared, and everyone currently in the group or working on the projects likes the candidate. Other times, it is less clear, even for PIs who have some sort of system in making their decisions. One PI described the decision-making process as follows: "it's kind of agonizing and I have no well-defined process for that final selection... We've had hires where one person stood out, we've had hires where we've had huge arguments and, in the end, we made a big blunder. It's very much a hit or miss, human process."

The PIs who considered candidates without a PER or social science background did not have any distinct means of evaluating their candidates. The candidates they hired still need to demonstrate some experience with working on education problems in some capacity. One PI gave the example that a candidate would need to demonstrate experience with evaluating student reasoning. The rationale for being interested in candidates without a PER background was succinctly described by one PI: "[those transitioning to PER] can add a different dimension to the research." Particularly with some of the course transformation work, candidates with a traditional physics Ph.D. tend to have more experience and vested interest in areas such as developing student expertise in experiments than someone with a Ph.D. in PER.

\section{How satisfied are PIs with the postdocs they hired?}

We were interested in whether PIs were satisfied with the postdocs they hired and if dissatisfied, whether the hiring process could be improved so that PIs could identify any issues. Of the eight PIs, seven tended to be overall satisfied with their postdocs because the postdoc did the job as expected. One PI measures their satisfaction with their postdocs by whether their postdocs "find their way," i.e., finds a career path rather than counting publications or that the postdoc goes into a tenure-track position. This PI felt that their postdocs have been able to do that.

Although most PIs were overall satisfied with their postdocs, three PIs reported having some postdocs with whom they were not satisfied. Two PIs report that they have had postdocs who were not able to do the tasks for the jobs. One PI reported that a postdoc simply did not do the work. Another PI reported that the postdoc was just not a good personality fit and the contract was not renewed. One PI had mixed experiences with their postdocs, but they also acknowledged those postdocs did well in their careers: "Even the postdocs who I thought didn't work out that well- they still got good jobs! No one was broken from the experience." Only one PI who was dissatisfied changed hiring practices. For subsequent hires, they decided to inquire more about "soft skills," e.g., how one works in a group setting.

\section{Postdoc results}

Part of the process of becoming a PER postdoc is deciding that becoming a postdoc is the next career move. The reasons to become a PER postdoc vary. Our postdoc sample had the following reasons for opting to become postdocs, including,

- Transitioning from traditional STEM $(N=4)$

- Were not hired for a more permanent position $(N=3)$

- Transitioning to a different research area within PER $(N=3)$

- Keeping career options open $(N=1)$

- Other reasons $(N=1)$

\section{How do postdoc candidates find potential positions?}

While we asked postdocs about how they found the position that they accepted, they often provided information about their general search. These results are in Table VI. The popular ways for successful postdocs to find positions usually involve some connection to the PER community: a close tie (e.g., an advisor), a weak tie (e.g., acquaintance), or networking at a conference. One postdoc said that attending AAPT and Physics Education Research Conference (PERC) meetings was useful for making initial 
TABLE VI. How postdocs searched for positions. Interviewees used multiple methods, so the totals are much larger than the sample size.

\begin{tabular}{lc}
\hline \hline & Postdoc $(N=13)$ \\
\hline Close tie (e.g., advisor, colleague) & 5 \\
Weak ties (e.g., acquaintances) & 5 \\
Networking at a professional conference & 5 \\
DBER-specific websites (e.g., PERJobs blog) & 3 \\
General academic job sites & 1 \\
List-servs & 0 \\
\hline \hline
\end{tabular}

contacts with PIs and then setting up more formal interviews at subsequent meetings.

\section{How do postdoc candidates decide whether to accept an offer?}

Interviews are not just for PIs to make a decision on who receives an offer. They are an opportunity for candidates to determine whether they want the job. While most postdocs said that liking the group was important $(N=11$ out of 13$)$, the position that they accepted was also frequently their only offer $(N=8$ or $61.5 \%)$. Some simply did not apply to multiple positions. Some did and accepted the first offer they received. Of the five who had multiple offers, they mostly chose their postdoctoral position based on the research being done. One postdoc did consider the research group dynamics. One place where they received an offer seemed to have poor team dynamics, including a female researcher who kept being interrupted during a talk. To that postdoc, this suggested the environment was unsuitable.

\section{How satisfied are hired postdocs with the postdoc experiences?}

PER postdocs in this study were overall satisfied with their positions, with nine able to continue onto more permanent jobs. The ones who have not were still postdocs when they were interviewed. While not everyone ended up in a tenure-track position or even a research position, they felt that the postdoctoral position was useful for their current career. They felt that the skills they developed, such as evaluating projects and understanding research, transferred over to their jobs after being a postdoc.

Although all the postdocs we interviewed were satisfied with their positions, a few did acknowledge aspects of the postdoc experience that could be improved. Three commented on the professional development they received. All three would have liked more career mentoring, with one specifically mentioning help identifying nonacademic careers.

As we were interested in those who were transitioning into PER from a traditional STEM Ph.D. background, we looked at their satisfaction. While all four felt they were able to use the postdoc positions to transition into PER and were enthusiastic about the support they received from their postdoc research groups, they also felt that it was not an easy transition. They often described the transition as being akin to starting graduate school, except with less structure (e.g., coursework) and more competing responsibilities (e.g., coordinating aspects of the project). One interviewee who transitioned to PER described this.

Be prepared to feel stupid again. During your Ph.D., you become very well versed in your field. And academics, myself included, have big egos so one of the things that's hard when you transition from somewhere else into education research - at least I had to undergo this, an epiphany that "wait, I don't really know anything." I had way more than I thought I had to learn.

These interviewees noted that they still are working on their PER-related skills, even those who have moved on to more permanent jobs. One interviewee felt "fully there [as a researcher in PER] but I have a lot to learn... I have a good sense of what not to do but not what to do. I don't think anyone has a good sense of what to do ever, but I have pretty good sense of what not to do."

Additionally, one interviewee who transitioned to PER noted that some of the same issues that existed in their original physics research field also exist in PER, namely, having a work-life balance and the pressure to publish. While they were satisfied with the transition to PER, they realized that PER was still "very much embedded in academia."

\section{Advice from PIs and postdocs}

We lastly asked PIs and those who are or were postdocs if they had any advice regarding hiring or general matters regarding PER postdocs. Although some interviewees believed that PER postdoc hiring is similar to that of traditional physics postdocs, some of the advice indicates differences (e.g., ensuring PER postdoc positions are not teaching positions).

For PIs, thirteen of our interviewees offered the following advice:

- Make sure the PI can support the postdoc's success as a researcher $(N=5)$. As one interviewee pointed out, support for the postdoc does not strictly need to come from the PI but can also come from the group. One PI emphasized that during the interview, PIs should "be clear about what you are looking for. Be honest with postdoc about short amount of time, and what they might need to grow professionally for their next job." Another PI pointed out that this means that postdoc positions need to be research positions, rather than lecturer positions advertised as postdoc positions.

- Be open minded to candidates from diverse backgrounds (e.g., field, graduate school, etc.) $(N=4)$. Interviewees believed that there are valuable candidates 
who may not be readily obvious because they are not known in PER or have different but complementary skills. One PI remarked that "with a lot of really great people with different experiences, think very carefully about what would make your project successful, including people from places you've never heard of."

- Consider ways to make the postdoc positions more attractive $(N=3)$. One postdoc observed that the pay is relatively low compared to other STEM counterparts and stated this is true at multiple campuses, not just theirs. Two PIs linked low pay, lack of prestige, and more positions than candidates as reasons that make it challenging to hire PER postdocs. They suggested devising a way to create a more prestigious position or offering more pay.

- Have multiple conversations with potential hires $(N=2)$. This piece of advice was about getting to know the potential hire, as one 1-hour conversation is not sufficient to understand someone's skills and potential.

- Soft skills of the postdoc are important $(N=2)$. The relationship with the hired postdoc "should be collegial, because you will disagree with them and have strong conversations, so this should be someone you can work with well and connect with."

- Conferences are valuable for finding postdocs $(N=2)$. One PI suggested simply stopping by the graduate student gatherings and announce that there is a position available.

For prospective postdocs, eighteen interviewees offered the following advice:

- Think about whether the position is of interest and whether it will further job skills $(N=5)$. The interviewees pointed out that postdoc positions can be used for many reasons. One PI advised that prospective postdocs ask themselves the following: "Do they want to do something new and change? Or do they want to solidify skills from grad school?"

- Make sure there are opportunities to develop skills to be competitive on the job market $(N=4)$. Such skills mentioned included grant writing and teaching courses. Three of the postdoc interviewees noted that having classroom teaching experience is critical for faculty positions.

- Interact with PIs and research groups before you are formally looking for a position $(N=4)$. This not only helps potential candidates learn more about the PI and the research group, but also helps others become aware that potential candidates are looking. One PI noted that they hire informally and jobs come up at different points throughout the year.

- Think about work-life balance $(N=4)$. This includes not only the amount of time one might spend working but also other factors such as where the institution is located. PIs and postdocs both note that this is important. Personal lives did factor into several candidates' postdoc searches.
- Be proactive in letting others know about your job $\operatorname{search}(N=3)$. One PI recalled that they struggled to get a postdoc position and that their advisor was instrumental in helping them become a postdoc. One former postdoc stated that they are not an extrovert but can go into "...conference mode." They had the following advice for prospective postdocs: "Make conversations, meet people, even if it's not quite comfortable. People become familiar with who you are. Don't just hang out with your research group. Meet someone new every meal you can." This former postdoc noted that meeting people can be challenging for some and suggested that if someone knows they are shy or introverted, that they ask someone else, such as a friend or another graduate student, to help introduce them to others.

- Calibrate application materials to the job ad to emphasize interest and relevant skills $(N=3)$. Even though there is the perception that there are more PER postdoc positions than potential candidates, PIs still want to ensure that the candidate can do the job.

- Ask questions about the job $(N=3)$. Suggested questions include asking about autonomy, what aspects of the project are fixed and which are flexible. These questions were suggested because workstyle or parts of the project may not be of interest to the candidate.

- Exercise patience with oneself $(N=2)$. While not directly related to hiring, once postdocs start working, they may be overwhelmed. One interviewee noted that particularly with new projects, there is a "long pathway to getting something off the ground."

\section{DISCUSSION}

Given the diversity of potential candidates and the importance of postdocs for the field of PER, we were interested in what hiring looks like from both the PI and postdoc perspectives, and ultimately, in whether postdocs and PIs were satisfied with their experiences.

Both the job advertisements and interviews offer some insights into PER postdoctoral hiring. The job advertisement study demonstrates beyond anecdote that there are many positions and that PIs consider diverse doctoral backgrounds. This was of interest for hiring because it suggests prospective candidates might be suitable even if they are not currently in PER. This diversity is similar to BER, given the potential ways to demonstrate interest and skills in BER [13].

There is no standard way of hiring PER postdocs. Some PIs hire more informally than others. Hiring varies from position to position even with the same PI. Some of the PIs do use some of the practices highlighted in the hiring literature such as multi-stage interviews and involving multiple members of the project or group in the interviews. While there is a preference for in-person interviews, 
funding may not be available to bring candidates to the campus. Alternatively, conferences have been used for some in-person interviewing and may be a good alternative to bringing the candidate on campus.

When evaluating candidates, PIs are interested in whether the PI can provide good mentorship and whether the candidate is a fit for the project or group. While this has benefits for the group, e.g., Ref. [16], and good intentions, PIs could potentially be introducing biases that are irrelevant to the position and whether the candidate would fare well in the group. Some PIs are aware and proactive towards eliminating biased hiring using tools such as rubrics. The process of PIs assessing their ability to mentor a candidate is valuable so that the postdoc has a positive experience. However, it may be worthwhile examining if PIs as a collective group can mentor a diverse set of postdocs. Otherwise, while PER PIs may be providing quality mentorship for those who become postdocs, they may also inadvertently exclude others who are qualified and would bring important new perspective to the projects and the field at large.

Most of the postdocs in this study had one offer, the one they accepted, so there may not have been much decision making in terms of comparing groups. However, they also noted that liking the research group factored into accepting the offer. For the few who did have a choice, disliking the research group factors in declining offers. As the literature suggests, e.g., Ref. [18], candidates do make decisions based on what they observe during the interview. Both the literature and these data indicate that cultivating a welcoming group is important to attract postdocs.

Despite all the differences in hiring and the candidates, most PIs and postdocs were satisfied. The work was completed, and postdocs had the experiences they wanted. The PIs who had some unsatisfactory postdocs had straightforward reasons for being dissatisfied (i.e., the postdoc did not do the work as expected). Sometimes, extenuating circumstances on behalf of the postdoc contributed to this. However, the PIs cannot pinpoint what if anything they could have done differently during the hiring process. As no hiring process is perfect, there may be nothing during the hiring process that would suggest unsatisfactory work.

Still, there may be ways for PIs to set up work conditions to increase the chances of satisfactory work and experiences. The few postdocs who did voice challenges noted that more professional development regarding career mentoring would be useful. Some of the advice for postdocs may also reflect this, as interviewees suggested making sure the experience builds onto the desired career. Perhaps more information on what experiences and skills are needed for particular careers should be readily available so that candidates can ask questions and determine whether the position will support their career.

One of the motivations for this study was to learn about hiring postdocs who were transitioning from a traditional
STEM discipline to PER. Those who are transitioning from a traditional STEM discipline still must demonstrate the potential to do work in PER. The PIs felt that these postdocs have valuable experience to offer. Although those transitioning to PER have positive feelings regarding the postdoctoral experience, they often felt as though they were still learning PER-related research skills, even those who have completed their postdoctoral positions. These concerns were not voiced by those who have doctoral degrees in the social sciences or PER. It is unclear whether those who are transitioning to PER lack confidence or whether they have some important research skills to develop. If it is the latter, perhaps there are ways to make the transition a little smoother. Some possibilities include developing programmatic efforts for postdocs to help the transition to PER or even to start introducing these skills and knowledge in small ways during graduate school. The authors of the BER guide suggested that biology graduate students who are interested in BER attend a related conference, organize a brown bag lunch with BER speakers, and consider doing a small research project in BER [13]. These suggestions would work for physics graduate students who are interested in PER. While there still may be challenges, those transitioning may have a smoother adjustment if they have more familiarity.

One theme that stood out throughout the interviews was the importance of having ties to members of the PER community. In Table VI, postdocs described using contacts to find their positions. Some of the interviews, including more informal conversations to acquaint prospective postdocs to PIs, took place at conferences. The advice offered by interviewees implies some ties to PER, by suggesting PIs use the conferences to find candidates and for prospective PER postdocs to inform everyone that they are looking. This advice is not bad for those looking for candidates or postdoc positions. It reflects the common advice of "using your network," which is also mentioned as a job-seeking strategy in the BER guide [13]. However, the importance of having ties to PER to become a postdoc begs the question of whether the candidate pool is as large or diverse as it could be if PIs are primarily using their network. Other literature, e.g., Ref. [24], suggests that recruiting methods can exclude potential candidates. There are likely graduate students from related fields who might not know about PER or have ties to PER community members, so they might not know these positions exist. This is not say that social ties within PER should not be used, but that perhaps PIs should think strategically about how to spread the word to other disciplines.

These findings do not suggest a "right" way to do PER postdoc hiring, but we hope that they shed some light on this area and provide food for thought for graduate advisors, PIs, and future postdocs. Namely, we hope these results improve upon individual postdoc experiences and in turn support the success of PER as a field. 


\section{ACKNOWLEDGMENTS}

We thank the Physics Education Research Topical Group (PERTG) for supporting this work via a minigrant. We also thank our interviewees and those who have maintained the PERJobs blog [30]. We thank the individuals who contributed to the PER postdoc list we created.

\section{APPENDIX A: PI INTERVIEW PROTOCOL}

Appendix A is the interview protocol for PIs. Please note that the interviews were semi-structured, so additional questions were also asked for clarification or if the interviewee mentioned something of interest to this study.

(1) Would you please describe the most recent postdoc positions you have offered?

(a) Do you have ideal candidate in mind when you create the position?

(2) Once you have a position open, how have you found someone to fill the position for your most recent hires?

(a) How do candidates find out about the position?

(b) Is there an application process? If so, what materials do you require (writing sample, references)?

(3) How do you make your decision on whom to hire?

(a) What experiences and educational background factor into your decision?

(b) If they require an application What happens after an application is received?

(i) What items in the application materials moves someone forward to the next step? What items in the application materials mean someone will be less likely to move forward?

(c) If they require an interview What happens at the interview?

(i) What do you want to find out from the interview?

(ii) What questions do you find informative?

(d) If references are provided When contacting the candidate's references, what do you want to find out?

(i) Are you looking for specific information (e.g., interpersonal skills, ability to work independently) or just confirmation that the candidate's $\mathrm{CV}$ is accurate?

(e) What determines who receives an offer?

(4) Overall, how satisfied have you been with your STEM education postdocs and their work?

(a) Are there any differences you have noticed between those with traditional STEM Ph.D.s vs. those from social science backgrounds?

(5) Since hiring your first postdoc to now, has anything changed in your hiring process?

(a) If changes have been made Why have you decided to change the process? (b) If changes haven't been made Are there reasons why you haven't changed your hiring process?

(6) What advice would you provide for PIs hiring PER postdocs?

(7) What advice would you provide applicants hoping to become a PER postdoc?

(8) Is there anything else you would like to add?

\section{APPENDIX B: POSTDOC INTERVIEW PROTOCOL}

Appendix B is the interview protocol for postdocs (current and former). Please note that the interviews were semi-structured, so additional questions were also asked for clarification or if the interviewee mentioned something of interest to this study.

(1) Can you describe what you do as a postdoc?

(a) What is/are the project(s) about, and how have you been involved?

(b) How is your time allocated between projects within this position?

(2) Why did you decide to become a PER postdoc?

(3) How did you find this position? (Ascertain whether advertised or word of mouth)

(a) If word of mouth How do you know (contact)?

(4) What was the application process?

(a) What were the required components of the application?

(i) How did you choose your references?

(ii) Did you end up submitting additional materials?

(5) If they had an interview What was the interview like?

(a) What sorts of questions did they ask?

(b) Were you expected to do anything else, like give a presentation?

(i) Did you have to meet with multiple people?

(6) Did you apply for other positions besides the one you are currently at?

(a) Did you interview for other positions?

(i) Were these PER postdoc positions or something else?

(b) What factors influenced your decision? (e.g. location, career goals, money)

(c) Did the interview influence your decision?

(7) What is your Ph.D. in (STEM ed, PER, pure STEM)? What is your background? Do you feel your graduate work or other work experience prepared you for this position?

(8) In retrospect, are there things you wish you could have asked or known before doing this position?

(a) How satisfied have you been with your postdoc? 
(b) Do you feel this experience was valuable to your career goals?

(9) What advice would you provide for PIs hiring PER postdocs?
(10) What advice would you provide applicants hoping to become a PER postdoc?

(11) Is there anything else you want to add that you think we would find useful?
[1] https://www.nsf.gov/pubs/1999/nsf9917/nsf9917.htm. Retrieved 30 January 2018.

[2] https://www.colorado.edu/sei/. Retrieved 30 January 2018.

[3] Committee to Review the State of Postdoctoral Experience in Scientists, and Engineers, Committee on Science, Engineering, and P. P., \& Policy and Global Affairs, The Postdoctoral Experience Revisited (National Academies Press Washington, DC, 2014).

[4] G. Vogel, Working conditions: A day in the life of a topflight lab, Science 285, 1531 (1999).

[5] National Research Council, Discipline-based education research: Understanding and improving learning in undergraduate science and engineering (National Academies Press, Washington, DC, 2012).

[6] C. Aschwanden, Professionalizing the postdoctoral experience, Cell 124, 445 (2006).

[7] B. Van Dusen, R. S. Barthelemy, and C. Henderson, Educational trajectories of graduate students in physics education research, Phys. Rev. ST Phys. Educ. Res. 10, 020106 (2014).

[8] R. S. Barthelemy, C. Henderson, and M. L. Grunert, How do they get here?: Paths into physics education research, Phys. Rev. ST Phys. Educ. Res. 9, 020107 (2013).

[9] B. Cantwell, Academic in-sourcing: International postdoctoral employment and new modes of academic production, J. Higher Educ. Policy Management 33, 101 (2011).

[10] Y. Meng and X. Su, The impact of postdoc training on academic research productivity: What are the gender differences?, Proceedings of the 2009 Atlanta Conference on Science and Innovation Policy (IEEE, Bellingham, WA, 2009), pp. 1-7.

[11] K. Kaplan, Postdoc or not?, Nature (London) 483, 499 (2012).

[12] H. Sauermann and M. Roach, Why pursue the postdoc path?, Science 352, 663 (2016).

[13] M. L. Aikens, L. A. Corwin, T. C. Andrews, B. A. Couch, S. L. Eddy, L. McDonnell, and G. Trujillo, A guide for graduate students interested in postdoctoral positions in biology education research, CBE-Life Sci. Educ. 15, 10 (2016).

[14] D. H. Kang, L. Davis, B. Habermann, M. Rice, and M. Broome, Hiring the right people and management of research staff, Western J. Nursing Res. 27, 1059 (2005).

[15] J. C. Min and B.H. Kleiner, How to hire employees effectively, Management Res. News 24, 31 (2001).

[16] D. E. Bowen, G. E. Ledford Jr., B. R. Nathan, J. G. E. Ledford, and B. R. Nathan, Hiring for the organization, not the job, Academy of Management Perspectives 5, 35 (1991).
[17] L. A. Rivera, Hiring as cultural matching: The case of elite professional service firms, Am. Sociological Rev. 77, 999 (2012).

[18] A. R. Wheeler, V. C. Gallagher, R. L. Brouer, and C. J. Sablynski, When person-organization (mis)fit and (dis)satisfaction lead to turnover: The moderating role of perceived job mobility, J. Managerial Psychol. 22, 203 (2007).

[19] M. Uhl-Bien and R. Marion, Complexity leadership in bureaucratic forms of organizing: A meso model, The Leadership quarterly 20, 631 (2009).

[20] I. O. Williamson and D. M. Cable, Organizational hiring patterns, interfirm network ties, and interorganizational imitation, Acad. Manage. J. 46, 349 (2003).

[21] J. D. Bragger, E. Kutcher, J. Morgan, and P. Firth, The effects of the structured interview on reducing biases against pregnant job applicants, Sex Roles 46, 215 (2002).

[22] S. A. Carless, Person-job fit versus person-organization fit as predictors of organizational attraction and job acceptance intentions: A longitudinal study, J. Occupational Organizational Psychol. 78, 411 (2005).

[23] S. A. Carless and A. Imber, The influence of perceived interviewer and job and organizational characteristics on applicant attraction and job choice intentions: The role of applicant anxiety, Int. J. Selection Assess. 15, 359 (2007).

[24] K. M. Neckerman and J. Kirschenman, Hiring strategies, racial bias, and inner-city workers, Social problems 38, 433 (1991).

[25] J. J. Sumanth and D. M. Cable, Status and organizational entry: How organizational and individual status affect justice perceptions of hiring systems, Personnel psychology 64, 963 (2011).

[26] B. Bird, H. Welsch, J. H. Astrachan, and D. Pistrui, Family business research: The evolution of an academic field, Family Business Rev. 15, 337 (2002).

[27] D. K. Molke, D. Laliberte-Rudman, and H. J. Polatajko, The promise of occupational science: A developmental assessment of an emerging academic discipline, Can. J. Occupational Therapy 71, 269 (2004).

[28] C. Holden, Behavioral medicine: An emergent field, Science 209, 479 (1980).

[29] D. C. Hambrick and M. J. Chen, New academic fields as admittance-seeking social movements: The case of strategic management, Acad. Management Rev. 33, 32 (2008).

[30] http://perjobs.blogspot.com/.

Correction: A reference and its citation in text have been removed. 